\title{
DE DRAMATURGO ADMIRADO A REFORMADOR DE COSTUMBRES: LA DERIVA ESPIRITUAL DE ALONSO REMÓN RESPECTO AL TEATRO
}

\author{
FROM ADMIRED PLAYWRIGHT TO REFORMER OF CUSTOMS: \\ ALONSO REMÓN'S SPIRITUAL DRIFT WITH RESPECT TO THEATER
}

RAFAEL MASSANET RODRIGUEZ

Universitat de les Illes Balears-IEHM

Recibido: $12 / 05 / 2020$

Aceptado: 23/09/2020

\section{RESUMEN}

La trayectoria literaria de Alonso Remón se inició con el teatro y su fama llegó a situarlo al nivel de Lope de Vega, reputado dramaturgo al que le unió una estrecha amistad. Se estima que llegó a escribir más de doscientas comedias, de las que apenas conservamos una decena. Sin embargo, a partir de determinado momento, abandonó las tablas para tomar el púlpito y dedicarse a la literatura espiritual y moral. El propósito de este artículo es indagar en las razones que le llevaron a tomar dicho camino y abandonar el género que tanto reconocimiento le dio. Para ello, tomaremos como referencia las diversas opiniones respecto al teatro que encontramos repartidas en su obra humanista y que demuestran cómo llego a pasar de concebir el teatro como un elevado juego de ingenio a un fenómeno descontrolado que podía acarrear el declive de la sociedad española.

Palabras clave: Alonso Remón, Teatro, Predicación, Literatura moral, Reforma de costumbres, Siglo de Oro. 


\section{ABSTRACT}

Alonso Remón's literary career began with the theater and his fame came to consider him at the level of Lope de Vega, a renowned playwright with whom he became close friends. It is estimated that he wrote more than two hundred comedies, of which we only have a dozen. However, from a certain point on, he left the stage to take the pulpit and dedicate himself to spiritual and moral literature. The purpose of this article is to investigate the reasons that led him to take this path and abandon the genre that gave him so much recognition. To do this, we will take as a reference the various opinions regarding theater that we find distributed in his humanist work and that show how he came to go from conceiving the theater as a high game of ingenuity to an uncontrolled phenomenon that could lead to the decline of Spanish society.

Keywords: Alonso Remón, Theatre, Preaching, Moral Literatura, Customs Reform, Golden Age.

¿Qué lleva a un dramaturgo reconocido y celebrado por sus contemporáneos a dejar de lado la escritura teatral? Es la pregunta que nos hacemos a la hora de abordar el estudio de la obra de Alonso Remón, quien se alejó de la escena para dedicarse por completo a la oratoria sagrada y los textos de carácter religioso y moral, con los que cosecharía, igualmente, grandes éxitos.

Sus inicios literarios los podemos situar con el soneto laudatorio publicado en los preliminares de Florando de Castilla, obra de Jerónimo de la Huerta. Poco tiempo después, en 1592, localizamos su primera pieza dramática conservada, el auto sacramental de San Juan Evangelista. A partir de este momento dedicaría sus esfuerzos al teatro y se relacionaría con las grandes figuras literarias del momento, quienes le dedicarían grandes alabanzas y encomios a su obra. Rojas y Villandrado sería el primero que lo mencionaría entre los grandes autores dramáticos que ilustran la comedia:

El gran Lupercio Leonardo,

Aguilar el de Valencia,

el licenciado Ramón,

Justianiano, Ochoa, Cepeda. ${ }^{1}$

1 Agustín de Rojas y Villandrado, El viaje entretenido (Madrid: Emprenta Real, 1603), disponible en http://www.cervantesvirtual.com/obra/el-viaje-entretenido--0/, acceso el 24/01/2020 
Cervantes, en su Viaje del Parnaso, se encuentra con seis personajes embozados, poetas encubiertos que, por decoro a su estado, encubren su identidad. Entre ellos se encuentra Remón:

Un licenciado de un ingenio inmenso

es aquel, y, aunque en traje mercenario,

como a señor le dan las musas censo;

Ramón se llama, auxilio necesario

con que Delio se esfuerza y ve rendidas

las obstinadas fuerzas del contrario. ${ }^{2}$ (332)

Este halago literario causó confusión entre algunos críticos, que no entendieron el motivo por el que el insigne autor del Quijote dedicara tales palabras a un supuesto desconocido. Cotarelo y Mori sugirió "la sospecha de si Cervantes confundiría a Téllez con Remón, a quien atribuye la paternidad de muchas obras"3. Rodríguez Marín también parece desconocer la identidad del mercedario y opina que podría tratarse de un posible nombre bajo el que se ocultara Tirso de Molina ${ }^{4}$. La vacilación vocálica entre "Remón" y "Ramón", fenómeno habitual en la época por otro lado ${ }^{5}$, llevaría a parte de la crítica a teorizar acerca de la existencia de dos autores diferenciados.

Cervantes volvería a laurear su labor dramática en el prólogo a sus Comedias:

Entró luego el monstruo de la naturaleza, el gran Lope de Vega, y alzóse con la monarquía cómica [...] Pero no por esto, pues no lo concede Dios todo a todos, dejen de tenerse en precio los trabajos del doctor Ramón, que fueron los más después de los del gran Lope. ${ }^{6}$

Tras él, otros autores son mencionados, como Mira de Amescua, Guillén de Castro o Vélez de Guevara, pero es importante destacar cómo el mercedario encabeza la lista de tan ilustres nombres y su obra se encuentra tras la estela de la de Lope. Sin embargo, de nuevo, algunos críticos han sugerido que Cervantes cometiera un error al nombrarlo, "queriendo sin duda aludir, con este alto elogio,

2 Miguel de Cervantes, Viaje del Parnaso, en Poesías, ed. por Adrián J. Sáez (Madrid: Cátedra, 2016), 332.

3 Emilio Cotarelo y Mori, prólogo a Comedias, I, de Tirso de Molina (Madrid: Biblioteca de Autores Españoles, 1906), XVII.

4 Miguel de Cervantes, Viaje del Parnaso, ed. Por Francisco Rodríguez Marín (Madrid: Bermejo, 1935), 57.

5 Manuel Fernández Nieto, Investigaciones sobre Alonso Remón: dramaturgo desconocido del siglo XVII (Madrid: Renacimiento, 1974), 9.

6 Miguel de Cervantes, Ocho comedias y ocho entremeses nuevos (Madrid: Castalia, 1999), III. 
al maestro Tirso de Molina" ". Su valor como adalid de los seguidores del Fénix de los Ingenios se refuerza cuando Quevedo lo nombra en su Buscón: "Y está ya de manera esto, que no hay autor que no escriba comedias, ni representante que no haga su farsa de moros y cristianos. Que me acuerdo yo antes, que si no eran comedias del buen Lope de Vega y Ramón, no había otra cosa"8.

Y el propio Lope de Vega alabó en múltiples ocasiones su labor literaria. Respecto a su vertiente poética, se lamentó que su amigo la abandonará en favor de otros senderos literarios:

Fray Alonso Ramón, puesto que olvida

las musas por la historia,

Cuenca le ofrezca duplicada gloria

a sus letras debida;

pues le ha dado más frutos, más tesoro,

si los libros son más que plata y oro,

entrando más por ti, dichoso Júcar,

que a España por la barra de Sanlúcar. ${ }^{9}$ (191)

Su reputación fue tal que llegaría a trascender fronteras. Franchi pone en boca de Lope de Rueda las siguientes palabras acerca del mercedario, cuando es presentado ante las divinidades: "Ramón dimanda un bagno di nettare per lisuoiversi, e che con qualche artificio si tirinotutti le suoiconcetti un poco piu verso la Corte, gia che non e possibile, in tutto, verso Lope" ${ }^{10}$. Este comentario, un tanto ácido sobre sus versos, hay que entenderlo en su contexto. Por un lado, Franchi desdeña en su obra a todos los autores dramáticos que presenta, a fin de ensalzar la figura de Lope. Por otro, el texto se escribió tiempo después de que abandonara el teatro y en un momento en el que sus comedias ya no se representaban y apenas existían testimonios impresos, por lo que se trata de una opinión sesgada. Sin embargo, el hecho de aparecer junto a otras grandes figuras resalta su consideración en los círculos dramáticos, aún más cuando viene de una pluma extranjera.

7 Amando Cotarelo y Valledor, El teatro de Cervantes (Madrid: Revista de Archivos, Bibliotecas y Museos), 36 .

$\begin{array}{ll}8 & \text { Francisco de Quevedo, La vida del Buscón, ed. por Fernando Cobo (Barcelona: Crítica, 2001), } \\ \text { 164. } & \\ 9 & \text { Lope de Vega, Colección escogida de obras no dramáticas, ed. por Cayetano Rosell (Madrid: }\end{array}$ Atlas, 1950), 191.

10 Fabio Franchi, Essequie poetiche o vero lamento delle muse italiane in morte del signore Lope de Vega (Venecia: G. Imberti, 1636), 65. 
Pese a que su fama teatral fue desvaneciéndose progresivamente, sus obras fueron puestas en valor al nivel de los más reconocidos autores de la época:"el doctor Antonio Navarro, en su Discurso apologético de las comedias, le celebró entre los más insignes poetas dramáticos de aquel tiempo" ${ }^{11}$. Incluso a principios del s. XIX sus comedias aun se conocían y destaca la refundición que Dionisio Villanueva y Solís llevó a cabo de una de ellas, titulada La Sevillana ${ }^{12}$.

No obstante, a pesar de todas las buenas consideraciones, Remón no prosperaría en la literatura dramática. Por el contrario, la dejaría de lado para abrazar la escritura humanista, moralista y religiosa. Esta decisión le llevaría, incluso, a alcanzar mayor reconocimiento, tal como demuestran las palabras cargadas de admiración que le dedicara fray Francisco de Benavides en el proemio a la Historia de la Orden de la Merced:

Muy docto y versado en humanas y divinas letras, como se vio bien y se conoció en sus doctos sermones que en esta Corte predicó y fue oído de gran concurso de gente y más claramente en los muchos libros que estampó en el discurso de su vida, tantos, que llegan a treinta y cuatro cuerpos, entre pequeños y grandes. ${ }^{13}$

Junto a estas alabanzas encontramos otras, a cargo de grandes autores, como Pérez de Montalbán, quien equipara sus textos con destacados predicadores de la talla de san Agustín o fray Luis de Granada: "El Padre Maestro fray Alonso Remón, predicador y coronista general de la sagrada religión de nuestra señora de las Mercedes, perpetuo estudiante y varón tan grande que tiene hasta hoy estampados en su nombre cuarenta y seis libros de diferentes materias"14. Lope de Vega también elogiaría esta faceta de su amigo:

Tan conocido en toda Europa por la dotrina de sus escritos y rara elocuencia en sus oraciones sacras [...] Lea pues quien gobierna y quien obedece libro tan importante [...] estimando el cuidado, estudio y diligencia de su autor, tan digno de los premios que le deben las dos repúblicas, pues con tanta elegancia, verdad y elocuencia las abraza. ${ }^{15}$

Sus sermones fueron muy apreciados y su habilidad para la predicación ampliamente reconocida. Maximiliano Céspedes, médico de su majestad y amigo

11 Vega, Colección..., 371.

12 BNE, ms. 15130.

13 Alonso Remón, Historia General de la Orden de Nuestra Señora de la Merced (Madrid: Luis Sánchez, 1633), XI.

14 Juan Pérez de Montalbán, Para todos (Barcelona: Francisco Caís, 1656), 144v.

15 Alonso Remón, Gobierno humano sacado del divino (Madrid: Luis Sánchez, 1624), VII-VIII. 
del mercedario, lo ensalzó como "uno de los grandes oradores cristianos de nuestra edad y siglos" ${ }^{\prime 16}$. Claramonte, por su parte, dedicó una de las composiciones a la figura de Ramón nonato, santo todavía sin canonizar. El asunto le sirve para hablar de una "trinidad" de ramones: el mencionado santo, Ramón de Penyafort y nuestro autor, de quien escribió:

Mas, si sois merced por dos

Ramones, en las acciones

otro Ramón os da Dios,

para que de tres Ramones

haya trinidad en vos.

Él con inmortal decoro

os cante, si no despierta

Téllez su acento sonoro, mas dejad que perlas vierta por sus labios pico de oro. ${ }^{17}(363-364)$

La obra incluye un índice final que referencia los autores citados, en el que alude, nuevamente, a su faceta dramática: "El padre maestro Ramón, de la Orden de los Comendadores de la Merced, insigne predicador y excelentísimo poeta". Bernardo de Vargas hizo hincapié en que la Orden de la Merced "tiene, además, dos poetas famosísimos: fray Gabriel Téllez y fray Alonso Remón, de los cuales el último publicó varios opúsculos"18.

Como hemos podido observar, Alonso Remón recibió halagos tanto por su faceta dramática como religiosa, y en ningún caso hallamos críticas por el desempeño de la primera. Si establecemos una comparativa entre las distintas etapas de su producción podemos observar como la primera, el teatro, cuenta con muchos menos testimonios, hecho que contrasta diametralmente con su obra humanística y religiosa, en la que se constata una voluntad de preservación, publicación y difusión. Remón nunca dejó por escrito ninguna relación aproximada del número de comedias o de sus posibles títulos. La única referencia a una posible cifra la encontramos en boca de Ordóñez de Ceballos, quien afirma que "escribió más de doscientas comedias"19. Esta elevada cantidad, que se

16 Antonio Liñán y Verdugo, Guía y avisos de forasteros (Alcalá de Henares: Juan Gracián, 1588), XII.

17 Andrés de Claramonte, Letanía moral (Sevilla: Matías Clavijo, 1613), 363-364.

18 Bernardo de Vargas, Crónica de la Orden de la Merced, II (Palermo: Ionanes Baptista Maringus, , 1622), 440.

19 Pedro Ordóñez de Ceballos, Tratado de los reinos orientales y hechos de la reina María y de sus antecesores (Jaén: Pedro de la Cuesta, 1629), XIV. 
contrapone a las comedias conservadas ${ }^{20}$, pudiera no corresponder con la realidad y ser una mera exageración con un propósito laudatorio. A este respecto, podemos señalar las más de cuatrocientas comedias que, presuntamente, escribiera Tirso de Molina: "Gusano es su autor de seda: de su misma sustancia ha labrado las numerosas telas con que cuatrocientas y más comedias vistieron por veinte años a sus profesores, sin desnudar, corneja, ajenos asuntos, ni disfrazar pensamientos adoptivos" ${ }^{21}$.

Respecto a su obra en prosa, en Casa de la razón y el desengaño da noticia de una veintena de libros publicados hasta $1625^{22}$, lo que ya indica una voluntad por dejar registro de la obra que consideraba representativa de su producción.

Se desconocen los motivos por los que Remón abandonó su relación con el teatro, ya que en ninguno de sus escritos presenta las razones precisas de su decisión. Sin embargo, a través del estudio de su biografía, así como de comentarios que se pueden localizar en sus distintos textos, podemos elaborar una posible teoría al respecto.

El hábito mercedario sería, sin duda, un importante condicionante para su retiro de la escena. La dedicación al servicio religioso se opondría a la escritura para el teatro, que tenía como objeto el vano entretenimiento, además de la relación que se establecía con grupos moralmente mal considerados, como las gentes del mundo de la farándula. Su trayectoria le encaminaría hacia el púlpito, desde donde predicaría la palabra sagrada y condenaría los malos hábitos, discurso que podría malinterpretarse si él mismo se encontrara entre los que denuncia. Esta sería una de las principales decisiones que le llevarían a distanciarse de su producción dramática anterior. Al apartarse de la escena, desentenderse de la situación de sus comedias respecto a las compañías y no mostrar ningún deseo de conservar sus textos, gran parte de su producción dramática acabaría por perderse. Para Remón solo existen tres maneras de servir a la Iglesia, entre las que, obviamente, el teatro no es una prioridad: "Una y la primera, el predicar la doctrina a las almas en los sermones. Otra el imprimir libros espirituales de vida de santos ejemplos y devociones. La tercera, el edificar iglesias" ${ }^{23}$.

20 Rafael Massanet Rodríguez, «Entre siete y doscientascomedias: hacia la fijación del corpus dramático de Alonso Remón», Studia Aurea 14 (2020): 463-486.

21 Tirso de Molina, Tercera parte de las comedias del Maestro Tirso de Molina (Tortosa: Francisco Martoreli, 1634), V.

22 Gumersindo Placer («Biografía del P. Remón, clásico español (II)», Estudios 3 (1948): 86-90) le atribuye hasta 50 textos.

23 Alonso Remón, Vida del caballero de Gracia (Madrid: Luis Sánchez, 1620), 90. 
Es evidente que sus compañeros de Orden tenían conocimiento de su actividad teatral previa a entrar en la congregación, aunque nunca fue objeto de crítica o escarnio por ello. Al contrario, llegaría a recibir encargos por parte de sus superiores para tareas relacionadas con la literatura, como la organización de las fiestas para la canonización de san Pedro Nolasco en Madrid o la composición de dos comedias para Ordóñez de Ceballos, a partir de su autobiografía Viaje del Mundo ${ }^{24}$. El caballero jienense dejó constancia de la petición que recibió el mercedario para retomar la pluma dramática:

En Madrid lo leyó Ramón, un fraile,

$\mathrm{y}$ visto tal portento

puso en obra su intento

y dijo su prelado: "Escribe y hazle

dos comedias famosas

(pues no son fabulosas),

$\mathrm{y}$ al vivo en casa las representemos,

y en verlas todos juntos nos holguemos. ${ }^{25}$

El propio Remón alude en los preliminares de la obra a este episodio: "La obediencia mandó que yo hiciese / aquestas dos comedias y escribiese / esta dedicatoria al propio dueño" ${ }^{26}$.Como podemos observar por sus palabras, la composición de estas comedias no parte de un deseo expreso del mercedario, quien ya se consideraba alejado de las tablas, sino de un encargo impuesto por un superior al que no se pudo negar.

Según Placer, el abandono del teatro respondería a un deseo de encaminarse a "los altos propósitos de virtud con que entraba en el estado religioso"27. A estas conclusiones llega en base a suposiciones, e influenciado por su propia relación con la Orden de la Merced, sin aportar pruebas documentales que apoyen su teoría. Como ya hemos señalado, Remón nunca escribió acerca de sus razones para abandonar la escritura dramática, pero sí dejó por escrito su opinión sobre la mala influencia que el teatro podía ejercer en la sociedad, especialmente en la juventud:

24 Miguel Zugasti, «El Viaje del mundo (1614) de Pedro Ordóñez de Ceballos o cómo modelar una autobiografía épica», Iberomania 58 (2003): 83-119; Rafael Massanet Rodríguez, «Entre la historia y la poesía: retrato dramático de Ordóñez de Ceballos, por Alonso Remón”, en De la reina al carpintero, biografias de época moderna, entre la historia y la literatura, ed. por Rafael Massanet, Miguel G. Garí y Francisco José García Pérez (Madrid-Porto: Sindéresis, 2020).

25 Ordóñez de Ceballos, Tratado..., XXV.

26 Ordóñez de Ceballos, Tratado..., XXVII.

27 Placer, «Biografía del P. Remón, clásico español (II)», 67-68. 
Ni tampoco se había de permitir a la gente moza y de poca experiencia los entretenimientos y recreaciones de las comedias y espectáculos de los teatros, por los muchos daños que se pueden seguir, de que la mocedad poco experimentada haga el juicio que no debiera de lo que es burlas y lo tome de veras y se aficione a la golosina de los bailes descompuestos y los movimientos deshonestos, de las palabras obscenas y torpes, de los dichos de risa y burlas. Porque nuestra mala inclinación con facilidad se deja llevar y a quien no está desengañado no es menester mucho engaño para cebarle y cegarle, que aquel refrán y proverbio antiguo de que la estopa y el fuego estando junto no están bien, verdaderísimo es. ${ }^{28}$

Su preocupación reside sobre todo en los perjuicios que el teatro pudiera acarrear en mentes menos desarrolladas, como las de los niños y los infantes: "No se le ha de permitir al niño que vaya a ver espectáculos teatrales, ni fiestas, adonde se permite demasiada licencia a los bailes mujeriles, por los daños que causan en los corazones tiernos y en las inclinaciones fáciles que después se lloran en edades mayores" 29 .

Pero también guarda opiniones sobre el público femenino, pues, en su opinión, la mujer no sabía dominar sus pasiones y no tenía la capacidad para diferenciar entre ficción y realidad: "las comedias y los espectáculos de teatros, a nadie me parece que le está menos bien que a las mujeres, por lo fáciles que son en persuadirse y en creer, haciendo aprehensión de las burlas como si fuesen veras" 30 .

Las reflexiones del mercedario dejan traslucir su opinión acerca del público, pero también del tipo de teatro que se llevaba a cabo en su época, más alejado del realismo o de la historia y, por otro lado, centrado en lo fantasioso y en la exaltación de las pasiones. No podemos dejar de señalar, por otra parte, que esa tendencia era un reflejo del propio gusto del público, que demandaba más producciones de contenido similar. Remón se posiciona en contra del teatro del exceso, pero también del exceso de teatro.

Su mayor inquietud es el efecto directo que pudiera ejercer sobre la sociedad un entretenimiento lúdico tan cautivador, pero carente de mensaje moral o espiritual:

29 Remón, Entretenimientos, 108.

30 Remón, Entretenimientos, 21v. 
Y a la mi fe, que para decir verdad, que no se ha de temer poco el daño que hace esta costumbre continuada, que al muchacho que en teniendo uso de razón, en lugar de inclinarle a otro mejor ejercicio y entretenimiento, le habitúan sus padres a cada día oiga comedia y gaste el tiempo en otros ratos semejantes. Cuando se quiera retirar a mejores ocupaciones, que sea de 30 o 40 años, duro y áspero se le ha de hacer el arrancarle de los ojos y oídos el rato de la comedia. Y cuando la Republica y los que la gobiernan las quisieren quitar o del todo por algún caso triste o funesto, o interpolando los días y semanas y lugares por buena razón de estado, por la gente ocupada en sus oficios, que se distrae con la continuación y pierde la sustancia y ganancia de mayores ocupaciones, ¿cómo ha de llevar bien aquella comunidad plebeya que le quiten aquel rato de gusto a que estarán hecha? Y no es la menor lástima, que como el que se hace a comer veneno desde niño, ya no le mata, sino que le sirve de sustento. ${ }^{31}$

La falta de comprensión del propio público, del pueblo, es lo que despierta las inquietudes de Alonso Remón. El teatro, en sí mismo, no es nocivo, pero una incorrecta presentación frente a la audiencia puede derivar en malentendidos, en detrimento de las esforzadas enseñanzas que, desde el púlpito, los siervos de Dios predicaban.

En 1630 publicó una relación de las fiestas de canonización de san Pedro Nolasco, celebradas el año anterior. Nuestro autor fue el encargado de su organización y en el texto muestra sus reservas a la hora de contar con la representación de una comedia, pues consideraba que el contexto religioso no era el más propicio:

La parte que le toca a este libro de la relación de la comedía que fue la fiesta ultima desta solemnidad.

Terribles dos gigantes son el vulgo y la costumbre. El vulgo inexorable, desbocado. Y si se remite a él y no a otro, mejor juicio cualquiera disposición y acción pública. No hay que disuadirle de aquello que una vez apreció y estimó, y le dio nombre de bueno y loable, y cuádrale maravillosamente la definición que le aplicó Cornelio Tácito en el libro 20 de sus Anales: "Sine rectore est praeceps pavidum socors vulgus". Remitido a la cabeza y juicio del vulgo que de su voto no hay sino dar por perdido el suceso, porque ya se muestra muy furioso, ya cobarde, ya se despena, ya se amilana. Y sabido de donde le nace esta confusión de malas elecciones, todo se origina de ser el 
vulgo. Y la plebe, tan grande, idolatra el uso y costumbre, ora sea bueno, ora malo. Y llegarle a tocar en este punto es romper con todo, porque si en todos, como enseñó Aristóteles en sus Problemas, en la sección 28: "consuetudo rationem habet naturae", o en la otra versión: "iam enim in naturae habitum ferme absoluitur", que la costumbre viene a tener fuerza de naturaleza, y querer atropellarla y rendirla es querer quitar la vida a quien se vale della: "Organtum more pugnare, cum diis naturae repugnare".

No le parece a lo común del pueblo que hay fiesta si no hay comedia y representación. Y al final salió el vulgo con la suya, que hubo de haber comedia. Que, habiendo de haberla, se procuró la escribiese, como la escribió, Lope de Vega Carpio, monstruoso ingenio, peregrino en la facilidad, galante en la dulzura, único maestro en este arte, primero en ella, sin que se puedan prometer las plumas poetas y teatros españoles otro segundo. Compuso una comedia de la vida de Nuestro Glorioso Padre y de parte de su triunfante vida, tan bien argentada y hermoseada de tantas farsas y sainetes cómicos, y aun de adornos enfáticos y apariencias misteriosas, que demás de tener lo que confesó Horacio, mezclando a lo útil lo dulce, remató las fiestas con nueva sazón, dando mucho y bueno que oír y ver. Y ver a quien había oído y visto tanto en todo el discurso desta solemnidad. ${ }^{32}$

Como leemos, se le encargó la composición de la comedia a Lope de Vega, tanto por su gran popularidad y la amistad que le unía a Remón, como por la garantía de que se llevara a cabo una representación digna del acontecimiento que se celebraba. Algunos críticos han resaltado el hecho de que no encargara la obra a su compañero de Orden, fray Gabriel Téllez, y aducen razones de rivalidades y envidias. Si tenemos en cuenta que en estas fechas ya había sucedido el episodio de la Junta de Reformación, es comprensible que Remón no quisiera contar con su presencia en los festejos. La participación de un dramaturgo condenado por "comedias que hace profanas y de malos incentivos y ejemplos" contravendría el castigo impuesto y podría empañar las festividades, no a ojos de un entregado público, sino de los censores y moralistas. Por otra parte, es comprensible que un autor volcado en la reforma de las costumbres, ante la tesitura de incluir una comedia, se aleje de la polémica y opte por la seguridad que le brinda Lope de Vega.

Vincent-Cassy ha querido ver en las palabras de Remón un recelo expreso hacia la problemática del teatro hagiográfico: 
Declara haber sido hostil al encargo de una obra para ese pueblo de pasiones incontrolables con ocasión de la canonización del santo fundador de su orden. En efecto, aunque dramaturgo, es de los que recelan del teatro hagiográfico, al considerar que este género poético, fundamentalmente contrario a la moral cristiana, es un lugar de depravación. Pero he aquí que el pueblo al que se destinan estas celebraciones no puede pasarse de una obra de teatro. "No ay fiesta si no hay comedia". Remón debe admitir que el teatro es un ingrediente indispensable del ritual de canonización. ${ }^{33}$

No obstante, si tenemos en cuenta las declaraciones anteriores, es evidente que su opinión no se limita a un género concreto, sino que se extiende a toda representación dramática. Incluso llega a reafirmarse en su opinión, con independencia del posible mensaje religioso o moral que contenga la comedia:

Desta ultima diferencia de juego [...] no es mi ánimo hablar ni tratar, como tampoco en las recreaciones y entretenimientos fue mi intento ni lo es admitir por tales a la comedia, ni espectáculos de teatros, ni bailes, ni danzas, digo habiendo en ellos y en ellas sobrada continuación y demasiada permisión en las palabras descompuestas y movimientos torpes y aun en esto puede haber una reformación cristiana y una moderación cuerda. ${ }^{34}$

No podemos dejar de mencionar la teoría que Vázquez propone, en base a las investigaciones de Morocho Gayo. Según esta, la razón que explicaría su ausencia de las tablas y el hecho de no publicar sus comedias vendría dada por una prohibición explícita por parte del propio monarca:

Remón, licenciado en Teología por Alcalá, fue uno de los destacados — siguiendo a Arias Montano y otros - en desmentir la veracidad de los "bronces aparecidos en el Sacromonte de Granada". En ellos se hacían constar, en letras arábigas, las leyendas antiguas del catolicismo español. Esta actitud negativa, que fue la más lúcida y cierta, desagradó a Felipe II y demás Austrias. Quizá sea esta la causa de que Remón — vocación tardía-, después del ingreso y noviciado en Santa Catalina de la Merced de Toledo, se instale en la Merced de Madrid, sin que se mueva de ahí en toda su vida. ¿Quiso el rey

33 Cécile Vincent-Cassy, «Los santos, la poesía y la patria», Revista de historia Jerónimo Zurita 85 (2010): 87.

34 Remón, Entretenimientos, 25. 
tenerlo bajo su control? También se explicaría así el que no se haya atrevido a editar sus comedias. ${ }^{35}$

Efectivamente, en base a los documentos aportados, Remón parece que se relacionó con dicho grupo, aunque de manera periférica y no tan abanderado como sugiere Vázquez:

El grupo de intelectuales que dirigía Pedro de Valencia formaba una Academia, cuyo núcleo originario lo formaban: Gurmendi, traductor oficial de árabe en la Corte; Mendiola, teólogo jesuita; y Valencia... A estos se sumaría un grupo de intelectuales formado por "otros amigos", entre los que habría que citar al literato Alonso Remón, al teólogo Francisco de Borja, al doctor Luis Zapata, al licenciado Juan Moreno Ramírez, al experto en lenguas orientales Juan Bautista Hesronita, etc. ${ }^{36}$ (Morocho 319 )

No obstante, no existe ningún documento con su nombre o firma en el que hable del suceso o se le relacione: "Formó parte de los hombres del círculo de Pedro de Valencia, aunque en la bibliografía consultada y en la valiosa información oral que nos ha facilitado el poeta galaico y muy erudito P. Luis Vázquez, no se hace referencia a dicho asunto" "37. El único lugar donde encontramos su nombre es en uno de los autos ${ }^{38}$ del arzobispo de Sevilla, don Pedro de Castro:

Granada. A.S.G. legajo 5, ff. 812-817. Autos originales del provisor de don Pedro de Castro, arzobispo de Sevilla, por los que en virtud de los Breves de Clemente VIII se requiere con censuras a fray Alonso Remnón (sic), a Pedro de Valencia, al doctor Martín Berrotarán y Mendiola, al padre Francisco de Borja, a Francisco de Gurmendi, al doctor Luis Zapata y a Juan Moreno Ramírez para que no hablen ni en pro ni en contra de los libros, como mandaba $\mathrm{Su}$ Santidad en los Breves, lo que ofrecieron cumplir. ${ }^{39}$ (Morocho 148)

Como indica Morocho Gayo, "se trata de un documento falsificado"40, por lo que debemos dudar de su autenticidad y de los nombres que figuran. No obstante, para Vázquez supone la prueba evidente que demuestra el motivo de la ausencia de comedias editadas y de "por qué Remón no desempeñó cargos en la

35 Luis Vázquez, «El mercedario Alonso Remón, comediógrafo (1561-1632)», en Paraninfos, segundones y epígonos de la comedia del Siglo de Oro, ed. por Ignacio Arellano (Barcelona: Anthropos, 2004), 42-43.

36 Pedro de Valencia, Obras completas, IV, ed. por Gaspar Morocho Gayo (León: Universidad de León, 1999), 319.

37 Valencia, Obras completas, 323.

38 Archivo de la Abadía del Sacromonte de Granada, legajo 5, ff. 812-817.

39 Valencia, Obras completas, 148.

40 Valencia, Obras completas, 148. 
Orden de la Merced — como Tirso, por ejemplo—, salvo el oficio de cronista; y permaneció, a los pocos años de profesar, en la Merced de Madrid toda su vida. Probablemente, los reyes quisieron tenerlo bajo control"41.

Esta teoría no se sostiene y carece de sentido. En primer lugar, cuando en 1618 se publica dicho documento, Remón hace mucho tiempo que se encuentra residiendo en Madrid y que ha dejado de escribir comedias ${ }^{42}$. La última que conocemos antes de esa fecha data de 1606, Grandezas de Madrid. Posteriormente, como ya hemos indicado, publicaría El Español entre todas las naciones y clérigo agradecido, por mandato de un superior y en una colección miscelánea que incluye a otros autores. En segundo lugar, no debemos olvidar que la obra de Remón también se compone de escritos humanistas, morales y religiosos, vehículos de mayor peso que el teatro para difundir esas teorías que, supuestamente, le prohíben divulgar. Tanto antes como después de la hipotética censura, Alonso Remón continuó publicando su obra sin mayores complicaciones, al tiempo que obtuvo el éxito y reconocimiento de sus contemporáneos. No podemos dejar de remarcar que nuestro autor ocupa una posición pública y privilegiada, como es el púlpito. En ningún momento se le prohíbe continuar con su labor como predicador e, incluso, escribe varios libros al respecto, lugares, nuevamente, propicios para poner en duda la veracidad de los plomos.

Vázquez desconoce, o no tiene en cuenta, las opiniones de Remón respecto al teatro para valorar su decisión de no publicar sus comedias, ni tampoco la dedicación religiosa que influyó en su producción literaria. Este hecho provoca que proyecte una opinión sesgada del autor que, en demasiadas ocasiones, se ve confrontada directamente con la figura de Tirso de Molina. Hay que precisar que estos dos autores mercedarios no llegaron a escribir para el teatro en la misma época, por lo que la supuesta rivalidad en la que se ha insistido no debe interpretarse dese una óptica literaria, sino moral.

En conclusión, el abandono del teatro por parte de Alonso Remón no responde a una postura contraria al mismo per se. Su oposición se debe al hecho teatral, la representación por parte de una compañía ante un público, no hacia el género literario. De otro modo, no se podría comprender ni la amistad que le continuó uniendo a reconocidos dramaturgos de la talla de Lope de Vega o Pérez de Montalbán, entre otros, ni tampoco el haber compuesto dos comedias por encargo una vez se hubo retirado. Sin duda, la particularidad de haber sido escritas para no ser representadas influyó en que tomara tal decisión.

41 Vázquez, «El mercedario Alonso Remón, comediógrafo (1561-1632)», 44.

42 La última comedia que conocemos antes de esa fecha data de 1606, Grandezas de Madrid. 
Tal como hemos podido observar, este género le reportó grandes reconocimientos por sus contemporáneos, incluso una vez retirado del mismo. Pero, a medida que fue siendo consciente del impacto negativo que la ficción y la exaltación de las pasiones ejercía sobre un publico fácilmente impresionable, orientó su carrera literaria hacia textos más provechosos para la sociedad. Su cruzada en hábito mercedario le encaminaría a una reforma de las costumbres y a un intento de prescindir del teatro como un espectáculo omnipresente que debía incluirse por fuerza en todo tipo de circunstancia, pese a que no siempre se produjera el contexto más adecuado. Con pesadumbre exclamaría Remón que "no hay fiesta si no hay comedia y representación", expresión que encapsula la manera de entender el ocio, y por qué no la vida, en la España del s. XVII.

\section{REFERENCIAS BIBLIOGRÁFICAS}

Cervantes, Miguel de. Ocho comedias y ocho entremeses nuevos. Madrid: Castalia, 1999.

Cervantes, Miguel de. Viaje del Parnaso, en Poesías. Ed. por Adrián J. Sáez. Madrid: Cátedra, 2016.

Claramonte, Andrés de. Letanía moral. Sevilla: Matías Clavijo, 1613.

Cotarelo y Mori, Emilio. "Discurso preliminar". En Tirso de Molina. Comedias, I. Ed. por Emilio Cotarelo y Mori. Madrid: Biblioteca de Autores Españoles, 1906.

Cotarelo y Valledor, Armando. El teatro de Cervantes. Madrid: Revista de Archivos, Bibliotecas y Museos, 1915.

Fernández Nieto, Manuel. Investigaciones sobre Alonso Remón: dramaturgo desconocido del siglo XVII. Madrid: Retorno Ediciones, 1974.

Franchi, Fabio. Essequie poetiche o vero lamento delle Muse italiane in norte del Signore Lope de Vega. Venecia: G. Imberti, 1636.

Huerta, Jerónimo de. Florando de Castilla, lauro de caballeros. Alcalá de Henares: Juan Gracián, 1588.

Liñán y Verdugo, Antonio. Guía y avisos de forasteros. Madrid: Viuda Alonso Martín, 1620.

Massanet Rodríguez, Rafael, "Entre la historia y la poesía: retrato dramático de Ordóñez de Ceballos, por Alonso Remón". En De la reina al carpintero, biografias de época moderna, entre la historia y la literatura, editado por Rafael Massanet, Miguel G. Garí y Francisco José García. Madrid-Porto: Sindéresis, 2020.

Massanet Rodríguez, Rafael. "Entre siete y doscientas comedias: hacia la fijación del corpus dramático de Alonso Remón”. Studia Aurea 14 (2020): 463 486. 
Ordóñez de Ceballos, Pedro. Tratado de los reinos orientales y hechos de la reina María y de sus antecesores. Jaén: Pedro de la Cuesta, 1629.

Ordóñez de Ceballos, Pedro. Viaje del mundo. Madrid: Luis Sánchez, 1614.

Pérez de Montalbán, Juan. Para todos. Barcelona: Francisco Caís, 1656.

Placer, Gumersindo. "Biografía del P. Remón, clásico español (I)". Estudios 2 (1948): 99-127.

Placer, Gumersindo. "Biografía del P. Remón, clásico español (II)". Estudios 3 (1948): 59-90.

Quevedo, Francisco de. La vida del Buscón. Ed. Fernando Cabo. Barcelona: Crítica, 2001.

Remón, Alonso. El español entre todas las naciones y clérigo agradecido. Jaén: Pedro de la Cuesta, 1629.

Remón, Alonso. Entretenimientos y Juegos honestos. Madrid: Viuda de Alonso Martín, 1623.

Remón, Alonso. Fiestas solemnes y grandiosas. Madrid: Imprenta del Reino, 1630 .

Remón, Alonso. Gobierno humano sacado del divino. Madrid: Luis Sánchez, 1624.

Remón, Alonso. Historia General de la Orden de Nuestra Señora de la Merced. Madrid: Luis Sánchez, 1633.

Remón, Alonso. Vida del Caballero de Gracia. Madrid: Luis Sánchez, 1620.

Rodríguez Marín, Francisco (ed.). Miguel de Cervantes. Viaje del Parnaso. Madrid: Bermejo, 1935.

Rojas Villandrado, Agustín de. El viaje entretenido. Madrid: Emprenta Real, 1603. Disponible en http://www.cervantesvirtual.com/obra/el-viaje-entretenido--0/. Acceso el 24/01/2020.

Rosell, Cayetano (ed.). Miguel de Cervantes. Obras completas, XII. Madrid: Rivadeneyra, 1864.

Tirso de Molina. Tercera de las comedias del Maestro Tirso de Molina. Tortosa: Francisco Martoreli, 1634.

Valencia, Pedro de. Obras completas, IV. Ed. por Gaspar Morocho Gayo. León: Universidad de León, 1999.

Vargas, Bernardo de. Crónica de la Orden de la Merced, II. Palermo: Ionanes Baptista Maringus, 1622.

Vázquez, Luis. "El mercedario fray Alonso Remón, comediógrafo (15611632)". En Paraninfos, segundones y epígonos de la comedia del Siglo de Oro, editado por Ignacio Arellano, 41-49. Barcelona: Anthropos, 2004.

Vega, Lope de. Colección escogida de obras no dramáticas. Ed. por Cayetano Rosell. Madrid, Atlas, 1950.

Vincent-Cassy, Cécile. "Los santos, la poesía y la patria". Revista de historia Jerónimo Zurita 85 (2010): 75-94. 
Zugasti Zugasti, Miguel. "El Viaje del mundo (1614) de Pedro Ordóñez de Ceballos o cómo modelar una autobiografía épica". Iberomania 58 (2003): 83 119.

Rafael Massanet Rodríguez Instituto de Estudios Hispánicos en la Modernidad (IEHM), Universitat de les Illes Balears

Cra. de Valldemossa, km. 7.5

07122 Palma de Mallorca (España) https://orcid.org/0000-0001-9340-1708 
